\title{
EDITORIAL
}

\section{Overview of the pharmacy education and workforce development challenges and responses to the global pandemic of COVID-19 in Switzerland}

\author{
Astrid Czock \\ QualiCCare Association, Baden, Switzerland \& Swiss Society of Endocrinology and Diabetology, Baden, Switzerland
}

Correspondence

Astrid Czock

czock@qualiccare.ch
The COVID-19 pandemic changed pharmacy education permanently as it promoted and facilitated online learning for the pharmacy workforce. In regards to examinations, it did not affect the examination mode as exams could be performed under special precautions and respecting predefined safety concepts.
Switzerland is a federalist country with 26 individual cantonal governments deciding according to their regional needs, e.g. in healthcare. The Federal Government in Berne is responsible for decisions concerning all cantons such as national strategies, laws or ordinances, while their implementation falls upon the responsibility of the cantons. According to the Law on Epidemics, the Federal government overrules cantonal decision-making when a national state of emergency is pronounced. As this was the case on 16th March 2020, the Swiss government ordered a total lockdown: the population was asked to work from home if possible, and to reduce travel to only the absolutely necessary. Hospitals were to cancel or postpone all planned or elective surgeries and prepare for the special treatment of COVID-19 patients. As gatherings of more than five people were forbidden, all conferences and face-to-face meetings were cancelled and schools moved education online. General practitioners were either extremely busy or not at all or had the office open for a few hours a day (Schlup \& Wille, 2020). Pharmacies were often on the frontline and open: the easily accessible pharmacists acted as first responders for the population, as many did not dare to go a doctor out of fear of infection. Unfortunately, initially the government did not provide the pharmacists with sufficient information or protective material - an omission, which pharmaSuisse, the Swiss Pharmacists association, put forward to the government, resulting in the fact that for future pandemics, the government will consider pharmacists also being at the frontline. Consequently, for the current pandemic pharmaSuisse started sending regular updates and information on governmental decisions to their members, who appreciated this regular update during these unsure times. Compared to the same time in the preceding year, pharmacies had an increase in client frequency in the first two weeks of the lockdown, resulting in up to $60 \%$ more revenue on certain prescription and non-prescription medicines (Drobi, 2020). Later, population preferences changed and smaller district pharmacies continued to have more clients whereas larger pharmacies at train stations or in shopping centres were markedly less busy. Did these COVID-19 -imposed changes in the workforce also affect pharmacy education? To get a better overview on the impact of the pandemic on the different domains in pharmacy education, three pharmacists involved in the respective fields were asked for their inside view. 
The Law on Medical Professions in Switzerland (LMedP), regulates the university and postgraduate education as well as licensure, which includes livelong continuous education for medical doctors, chiropractors, pharmacists, dentists and veterinarians.

\section{Continuous education}

The LMedP requires all medical professionals to show proof of annual continuous education. Community pharmacists are required to show proof of 200 credits ( = four sets of eight hours) of continuous education annually. In the first days of the pandemic, continuous education was not the pharmacists' first priority. In addition, due to the lockdown, education providers were obliged to cancel or postpone all face-to-face courses, workshops and conferences. The accreditation body for continuous education, (Foederatio Pharmaceutica Helvetiae [FPH] Officine) decided in May 2020 to waive half of the required credits for 2020 and demand a proof of 300 credits (= six sets of eight hours) of continuous education for the years 2020 and 2021 combined. This decision came after, and corresponds to, the decision of the medical accreditation body (Swiss Institute of Medical Post- graduate and Continuous Education [ISFM]) who waived $50 \%$ of the required credits for 2020 for medical doctors (ISFM).

Before the COVID-19 pandemic, many continuous and postgraduate education providers had no, or only a few, online courses as pharmacists still preferred face-to-face encounters. As all face-to-face events stopped suddenly, many providers applied for short-time work compensation to the government to cut their running costs. Some providers had already been offering online education and continued their services. For others, who had not yet moved online, this was the opportunity to be proactive and take up the challenge. One postgraduate and continuous education provider responded quickly and moved all face-to-face courses to interactive webinars within less than two weeks. The experience proved them right as more and more pharmacists booked the online courses for further education.

The COVID-19 pandemic changed the educational environment permanently for both pharmacists and pharmacy technicians in Switzerland. Interactive online education is in demand, which was not the case a few years back, with currently 40-50 pharmacists and more than 200 pharmacy technicians and interacting daily in webinars via chat functions. Unlike pharmacy technicians, pharmacists prefer to keep their cameras turned off and many ask questions anonymously. The reasons are unknown, but could equally be a question of age or of culture.

More providers are now starting live streams or webinars as pharmacists see the advantages of following a course from the comfort of their living rooms. Current preferences tend to convenient on-demand webinars before live webinars.

From the viewpoint and experience of the past few months, a reduction of required continuous education credits did not seem necessary to the education providers, as they saw that time management for online courses was manageable for the pharmacists - even those at the frontline. The providers on the other hand, suffered from a financial loss.

\section{Postgraduate education and examinations 2020}

The LMedP requires a Federal postgraduate in community or hospital pharmacy for pharmacists directing a community or hospital pharmacy, respectively. With a Master's degree, pharmacists obtain the Federal license and can work in pharmacies but cannot direct a pharmacy. The Federal PG-titles in pharmacy require an additional two-year extra-occupational education while working $80 \%$ in a pharmacy. Since 2018, pharmacists without a PG-title cannot take over or open a new pharmacy in Switzerland, nor can they become the responsible director of a pharmacy. The PG-education in community pharmacy was amended in 2019, following the last Federal accreditation (FPH, 2019). All postgraduate programmes (as well as the graduate programmes) for all medical professions are assessed and accredited every seven years by the Swiss Agency of Accreditation and Quality Assurance (AAQ), mandated by the Federal Council and the Department of Internal Affairs. The new curriculum for the PG education in community pharmacy concentrates on seven roles of the pharmacist, defined according to the needs in the practice. The seven roles are adapted from the CanMEDs framework (Royal College of Physicians and Surgeons in Canada, 2020): pharmaceutical expert, communicator, inter-professional partner, scientist and educator, health coach, responsible leader and manager, and professional role model.

The final Board exam assesses the first role, the 'pharmaceutical expert'. The candidate's mentor in the pharmacy assesses all remaining 'roles' in practical assignments. Due to the pandemic, the Examination Board deferred all PG-examinations due in March 2020 to Spring 2021. 


\section{University education, Federal Examinations in Pharmacy 2020}

As the Medical Examination board cancelled their federal examinations and replaced them by a six-week internship in November 2020, the Examination Board in Pharmacy also discussed if they should adapt accordingly. The Federal examination in Pharmacy consists of three parts and takes place at precisely the same time in all three universities: a systematic multiple-choice examination assessed by the Institute of Medical Education in Berne (IML, 2020), an OSCE (Objective structured clinical examination) and a practical formulation of an extemporaneous product (including literature search) as well as two dosage calculations.

The Examination Board decided to proceed with the examinations applying a safety concept with interpersonal distance and face-masks. An additional obstacle for the Examination Board came up with the sudden passing of International Federation of Pharmacists (FIP) Fellow and FIP Distinguished Practice Award recipient Prof. Olivier Bugnon from Geneva University who was a Member of the Board and one of the main examiners for the OSCEs. It took two examiners to replace him for the examinations as well as in the Board until his succession is decided.

The examinations in 2020 proceeded as scheduled in September with approximately 200 candidates. Some students will have to re-sit, but 184 students passed and are now federally licensed pharmacists with a Master's degree (pharmaJournal, 2020). Feedback from the candidates was positive, stating they had more study time, especially for the multiple-choice part on the pharmacotherapy. Waiting time for the students was longer due to the safety concept.

In spite of the challenges posed by the pandemic, the University of Berne set up a new pharmacy education program to the Master's degree due to start in the autumn term of 2020. So far, pharmacy students had to transfer after the Bachelor's degree to the Universities of Geneva or Basel or the Federal Technical Institute of Zürich. In Berne, the Pharmacy School is part of the Medical faculty.

The University of Berne installed a new Chair in Primary Care, jointly held by a Medical Professor and by a Pharmacy Professor, and focusing on patient-oriented care and interprofessional collaboration. This evolution is highly welcomed by the Swiss Society of Family Medicine and pharmaSuisse. This initiative at the foundation training level (FIP WDG 2) simultaneously addresses the FIP Workforce Development Goal 8 'Working with Others', inter-professional (IP) education. In Berne, an IP-workshop is a compulsory module of ten hours in the new curriculum. With this joint chair, the University of Berne is putting the other three pharmacy institutes under pressure to follow suite and implement primary care and IP-education.

With the advent of rapid SARS-CoV2-antigen tests, pharmacies can further show their contribution as important healthcare professionals. For the first time, the Federal Government has authorised pharmacists to provide a reimbursable service with these rapid-tests. General practitioners and ICU-nurses are willing to train pharmacists in their spare time as they realise the urgent demand for IP collaboration in the current situation. Now it is up to the pharmacists to take up the challenge and accept the hands offered by other professionals to work together (FIP DG 8) and advance their continuous professional development strategies (FIP DG 9) beyond the COVID-19 pandemic. Unfortunately, many pharmacists are still hesitant to provide rapid testing. One important excuse is that they cannot provide a safety concept in their pharmacy. Many prefer to not test than work with other pharmacists in the area, let alone work with other professions. Pharmacists need to overcome this individuality and embrace the global picture of providing healthcare working with others to address the challenges of future emerging viruses, antibiotic resistances, an ageing society and a rise of non- communicable diseases.

\section{Acknowledgements}

I would like to thank the following persons for their inside information on the current situation in regards to continuous and postgraduate pharmacy education as well as the Federal examination in pharmacy: Dr. Christina Ruob, CEO of medinform AG, a continuous and postgraduate education provider; Dr. Irmgard SchmittKoopmann, formerly of the department for education of pharmaSuisse; Dr. Christine Moll, Chair of the Federal Examination Board for Pharmacy, appointed by the Federal Council

\section{References}

AAQ [Swiss Agency of Accreditation and Quality Assurance]. (2020). Available at: https://aaq.ch/en/

Drobi, R. (2020). Communication by Swiss German Television and Radio Network, SRF, using IQVIA data Feb-May 2020 in comparison to 2019. Swiss Radio and Television. Available at: https://www.srf.ch/news/wirtschaft/apotheken-im-umsatztief-die -ruhe-nach-dem-sturm 
FPH [Foederatio Pharmaceutica Helvetiae]. (2019). Post graduate education-program Specialist in community pharmacy. Available at: https://www.fphch.org/documents/50227/79508/2019-05$\underline{22+\text { Weiterbildungsprogramm.pdf/ }}$

FPH [Foederation Pharmaceutica Helvetiae]. (2020). Formation continue. Available at: https://www.fphch.org/fr/formationcontinue

IML [Institute for Medical Education]. (2020). Available at: https://www.iml.unibe.ch/en/iml

ISFM [Institut suisse pour la formation médicale postgraduée] (2020). COVID-19: Formation continue. Available at: https://www.siwf.ch/fr/themes/covid-19/covid-19-formation-con $\underline{\text { tinue.cfm }}$

Le Conseil federal. (2020). Loi federale sur les professions medicales universitaires: (Loi sur les professions medicales, LMedP). Available at: https://www.admin.ch/opc/fr/classifiedcompilation/20040265/index.html

pharmaJournal. (2020). Available at: https://www.pharmasuisse. $\mathrm{org} / \mathrm{fr} / 1476 /$ Produits-destinés-aux-connaissances-pharmaJournal11-2020.htm?ShopArticle=2353554. 11(2020), 28-29

Royal College of Physicians and Surgeons of Canada. (2020). CanMEDS framework of the Royal College of Physicians and Surgeons of Canada . Available at: http://www.royalcollege.ca/ rcsite/canmeds/canmeds-framework-e

Schlup, J., \& Wille, N., (2020). Corona-Pandemie: Situation der Ärztinnen und Ärzte in der Schweiz. Schweiz. Ärzteztg. 101(2930), 882-884 